Al-Azhar Bull. Sci. Vol. 19, No. 2 (Dec.): pp. 183-192, 2008.

\title{
REACTIVITY OF 4-(4-METHOXYPHENYL)-1(2H)-PHTHALAZINONE TOWARDS SOME NUCLEOPHILES
}

\author{
NADIA .T. A. DAWOOD
}

Chemistry Department, Faculty of Science, Girls' Branch, Al-Azhar University, Nasr City, Cairo, Egypt.

\begin{abstract}
The reactivity of 4-(4-methoxy)phenylphthalazinone (1) towards halogen and sulphur nucleophils has been investigated. The influence of amino acids, hydrazines, acid hydrazides and sodium ethoxide on the products is discussed. The structures of the products have been assigned by elemental analyses and spectral data.
\end{abstract}

Key Words Convenient Synthesis of Functionally Substituted Phthalazines, Pyrazolophthalazine, Phthalazinopyridone and Triazolophthalazine Derivatives.

\section{Introduction and Discussion}

The promising biological activity of some phthalazines have stimulated recent interest in the syntheses of these ring system ${ }^{(1)}$.

Thus, interaction of 4-[(4-methoxy) phenyl] phthalazin-2-(1H) one $(1)^{(2)}$ with phosphorous oxychloride/phosphorous pentachloride mixture afforded the corresponding 4-substituted-phenyl-1-chlorophthalazine derivative (2) ${ }^{(3)}$. i) The mass spectrum of (2) showed a molecular ion peak at $\mathrm{m} / \mathrm{z} 270.5(53 \%)$ which was in accordance with its structure, ii) IR spectrum showed bands at $1665 \mathrm{~cm}^{-1}$ of $\gamma \mathrm{C}=\mathrm{N}$ and at $1075 \mathrm{~cm}^{-1}$ of $\gamma \mathrm{C}-\mathrm{Cl}$.

Treatment of (2) with glycine in boiling ethanol furnished a single product analyzed for the molecular formula $\mathrm{C}_{17} \mathrm{H}_{13} \mathrm{O}_{2} \mathrm{~N}_{3}$. This product was 5-(4-methoxy phenyl)-phthalazino[1,2-b] imidazoline-3-one (3) i) IR spectrum of (3) devoid $\gamma \mathrm{C}$ $\mathrm{Cl}$ and showed bands at $1670,1600 \mathrm{~cm}^{-1}$ due to $\gamma \mathrm{C}=\mathrm{N}, \mathrm{C}=\mathrm{C}$ and at $1720 \mathrm{~cm}^{-1}(\gamma \mathrm{N}$ $\mathrm{C}=\mathrm{O}$ imidazolinyl), ii) The mass spectrum of (3) showed a molecular ion peak at $(\mathrm{m} / \mathrm{z} 353)$.

Similarly, the reaction of 2 with anthranilic acid in refluxing ethanol afforded the corresponding phthalazino [1,2-b] quinazolinone $(4)^{(4)}$ in reasonable yield. The IR spectrum of (4) devoid $\gamma \mathrm{C}-\mathrm{Cl}$ and showed absorption bands at $1675 \mathrm{~cm}^{-1}$ of $\gamma \mathrm{C}=\mathrm{N}$

The applicability of compound (2) for the synthesis of heterocycles of expected bioresponse was investigated. Thus, compound (2) reacted with hydrazine hydrate and with 2- hydroxybenzoyl hydrazide afforded the corresponding hydrazine derivative (5) and the triazolo[4,3-b]phthalazine derivative $(6)^{(5)}$, the structure of (5) was established by i) IR spectrum which showed strong absorption bands at 1675, $3250 \mathrm{~cm}^{-1}$ of $(\gamma \mathrm{C}=\mathrm{N}, \mathrm{NH})$ and devoid of $\gamma \mathrm{C}-\mathrm{Cl}$ also the structure of (6) was inferred 
from i) ${ }^{1} \mathrm{H}-\mathrm{NMR} \delta 3.8\left(\mathrm{~s} ; 3 \mathrm{H}, \mathrm{OCH}_{3}\right), 9.1-10.1$ (br,s,1H,OH) and 7.25-8.5 (m,12.Ar$\mathrm{H})$, ii) IR spectrum devoid $\gamma \mathrm{C}-\mathrm{Cl}$ and showed bands at $1625 \mathrm{~cm}^{-1}$ of $\gamma \mathrm{C}=\mathrm{N}$.

The reaction of 2 with sodium ethoxide in boiling ethanol provided the corresponding $\mathrm{N}$ - substituted -1-ethoxy phthalazine (7), IR spectrum showed absorption bands at $1675 \mathrm{~cm}^{-1}$ of $\gamma \mathrm{C}=\mathrm{N}$ and devoid $\gamma \mathrm{C}-\mathrm{Cl}$.

The reaction of 1 with monochloro acetic acid in the presence of sodium hydroxide solution, yielded 4-substituted phthalazine-2-glycolic acid $(8)^{(6)}$, the structure of (8) was established by IR spectrum which showed strong absorption bands at $1710 \mathrm{~cm}^{-1}(\gamma \mathrm{C}=\mathrm{O})$ of acid, $1630 \mathrm{~cm}^{-1}(\gamma \mathrm{C}=\mathrm{N})$ and $3443-3280 \mathrm{~cm}^{-1}(\gamma \mathrm{OH})$. Treatment of (8) with salicylalaldehyde afforded the corresponding 4-[-substituted (phthala-zine-2-yl)-3-hydroxy styrene] $(9)^{(7)}$, its ${ }^{1} \mathrm{H}-\mathrm{MNR}$ showed bands at $\delta 3.8$ $\left(\mathrm{s}, 3 \mathrm{H}, \mathrm{OCH}_{3}\right), 6.8-8.2(\mathrm{~m}, 12-\mathrm{Ar}-\mathrm{H}$ and olefinic $\mathrm{H})$ and $10.5(\mathrm{~s}, 1 \mathrm{H}, \mathrm{OH})$. and its IR spectrum showed strong absorption bands at $1670 \mathrm{~cm}^{-1}(\gamma \mathrm{C}=\mathrm{N})$ and at $1610 \mathrm{~cm}^{-1}$ of $(\gamma \mathrm{C}=\mathrm{C})$.

4-substituted-phthalazine-1-thione (10) was obtained by the action of phosphorus pentasulphide on (1), the IR spectrum showed absorption bands at 3320, 2850, 2555, 1615 and $1255 \mathrm{~cm}^{-1}$ corresponding to $\gamma(\mathrm{NH}, \mathrm{C}-\mathrm{H}, \mathrm{SH}, \mathrm{C}=\mathrm{N}$ and $\gamma \mathrm{C}=\mathrm{S}$ respectively. The ethanolic solution of (10) with primary and / or secondary amines such as benzylamine and diphenylamine gave the corresponding 4- substituted-hydrazone derivatives $(11 \mathrm{a}, \mathrm{b})$. IR spectrum of $(11 \mathrm{a}, \mathrm{b})$ showed strong absorption bands at 3300 and $1620 \mathrm{~cm}^{-1}$ attributable to $\gamma(\mathrm{NH}$ and $\mathrm{C}=\mathrm{N})$ and devoid $(\gamma \mathrm{C}=\mathrm{S})$. Hydrazinolysis of (10) with hydrazine hydrate afforded the corresponding 4-substituted-1-hydrazinophthalazine $12^{(8)}$. i) ${ }^{1} \mathrm{H}-\mathrm{NMR} . \delta 2.8\left(\mathrm{~s}, 3 \mathrm{H}, \mathrm{OCH}_{3}\right)$, at $5.3\left(\mathrm{~m}\right.$. broad. $\left.3 \mathrm{H}, \mathrm{NH}, \mathrm{NH}_{2}\right)$ and 7.0-8.1 (m,8H,Ar-H) and 10.9 (br.s, 2H,NH). ii) IR spectrum showed stretching frequencies at 1930, 3300, $3200 \mathrm{~cm}^{-1}$ for $\gamma \mathrm{C}=\mathrm{N}, \gamma \mathrm{NH}_{2}$ and $\gamma \mathrm{NH}$ functions respectively. The reaction of (12) with benzaldehyde in the presence of pipridine afforded the corresponding 1-(benzylideneamino-)-4-substituted phthalazine (13). IR spectrum of 13 reveals the presence of $(\gamma \mathrm{C}=\mathrm{N})$ at $1595 \mathrm{~cm}^{-1}$ and $\mathrm{NH}$ absorption vibration occurred at $3215 \mathrm{~cm}^{-1}$.

Treatment of (10) with acrylonitrile afforded 4-(substituted)-1-(mercapto cyanoethyl) phthalazine (14) ${ }^{(9)}$.IR spectrum of 14 showed absorption bands at 2860 , 2210 and $1600 \mathrm{~cm}^{-1}$ due to $\gamma \mathrm{C}-\mathrm{H}, \mathrm{C} \equiv \mathrm{N}$ and $\gamma \mathrm{C}=\mathrm{N}$ respectively .

Treatment of (10) with phenylisothiocyanate afforded the corresponding 4(substituted)-1-(N-phenylthiocarbamoyl) mercapto phthala-zine (15). The IR spectrum showed absorption bands at 3320,1615 and $1255 \mathrm{~cm}^{-1}$ corresponding to $\gamma(\mathrm{NH}, \mathrm{C}=\mathrm{N})$ and $(\gamma \mathrm{C}=\mathrm{S})$ respectively. Similarly, Alkylation of (10) with ethyl bromoacetate in the presence of acetone and anhydrous potassium carbonate yielded 4-(substituted) -phthalazine-1-thioglycolic ester $(16)^{(10)}$.The IR spectrum of 16 
showed strong absorption bands at $1745 \mathrm{~cm}^{-1}\left(\gamma \mathrm{C}=\mathrm{O}\right.$ of ester) and $1630 \mathrm{~cm}^{-1}$ $(\gamma \mathrm{C}=\mathrm{N})$.

The reaction of (16) with anthranilic acid in boiling butanol gave the corresponding 2-(substituted)-4H-3, 1 benzoxazinone $(17)^{(11)}$. i) The mass spectrum of (17) showed a molecular ion peak at $(\mathrm{m} / \mathrm{z} 427)$ which is in accordance with the proposed structure. ii) the IR spectrum exhibited bands at $1760 \mathrm{~cm}^{-1}$ (oxazinone $\gamma \mathrm{C}=\mathrm{O}), 1635(\gamma \mathrm{C}=\mathrm{N}$ ) and $1605(\gamma \mathrm{C}=\mathrm{C})$. Hydrazinolysis of $(16)$ with hydrazine hydrate gave the corresponding 2- substituted -1-(N-mercapto methyl hydrazide-4substituted phthalazine (18) ${ }^{(12)}$. IR spectrum showed absorption bands at 3300,1670 and $1620 \mathrm{~cm}^{-1}$ to $\gamma(\mathrm{NH}, \mathrm{C}=\mathrm{O}$ and $\mathrm{C}=\mathrm{N})$ respectively.

The structure of these products were confirmed from their analytical data ( c.f. Table 1 ).

\section{Experimental Section}

All melting points are uncorrected. IR spectra were recorded $(\mathrm{KBr})$ on a PYE Unicam SP-1000 spectrophotometer ${ }^{1} \mathrm{H}-\mathrm{NMR}$ spectra were recorded on a Gemini 200-MHZ spectrophotometer using TMS as an internal standard and DMSO-d6 as a solvent.

Chemical shifts are expressed in $\delta$ ppm. Mass spectra were run on a Mat 112 instrument

Compounds 1 and 2 were prepared according to literature procedures ${ }^{(2,3)}$.

Reaction of 4-[4(-methoxy) phenyl] Phthalazinone with a mixture of Phosphorus oxychloride phosphorus Pentachloride:Formation of 4-(substituted)-1- chloro Phthalazine 2.

A mixture of $1(0.01 \mathrm{~mol})$ and phosphorus pentachloride $(0.01 \mathrm{~mol})$ in $5 \mathrm{ml}$ of phosphorus oxychloride was heated on steam-bath for $2 \mathrm{hrs}$. it was then Poured into ice-water while stirring the solid obtained was filtered off, washed well with cold water, dried and recrystallized from ethanol to give 2 as a gray crystals (Table 1).

\section{Reaction of 2 with Amino-acids : Formation of 3 and 4}

A mixture of $2(0.01 \mathrm{~mol})$ and amino acids namely glycin and/or anthranilic acid (0.01 mol )in $30 \mathrm{ml}$ ethanol and little amount of water was heated under reflux for 8 hrs after cooling, it was poured into ice-water and the product that obtained was had washed and recrystallized from ethanol to give 3 as brownish red crystals and 4 as yellow crystals (Table 1).

\section{Reaction of 2 with Hydrazine hydrate : formation of 5}

Hydrazine hydrate $(1 \mathrm{ml})$ was added to $2(0.01 \mathrm{~mol})$ in ethanol $(40 \mathrm{ml})$ and refluxed for 6.hrs. Left to cool. Then poured it in to ice dilute $\mathrm{HCl}$. The solid product 
was washed well and recrystallzied from ethanol to give 5 as yellow crystals (Table 1).

\section{Reaction of (2) with Acylhydrazine: Formation of 6.}

Amixture of $2(0.01 \mathrm{~mol})$ acylhydrazine namely p-hydroxy benzoyl hydrazine in (40ml) of butanol was heated under reflux for $18 \mathrm{hrs}$.the solid separated after concentration and cooling was filtered off and recrystallized from ethanol to give 6 as white crystals (Table 1).

\section{Reaction of (2) with Sodium ethoxide:Formation of (7)}

A mixture of $2(0.01 \mathrm{~mol})$ of sodium ethoxide (prepared by dissolving $1.1 \mathrm{~g}$ of sodium metal in $35 \mathrm{ml}$ of absolute ethanol), was heated under reflux for $3 \mathrm{hrs}$. The reaction mixture was cooled, acidified with dilute $\mathrm{HCl}$. and the solid that separated was filtered off, dried and recrystallised from ethanol to give 7 as beige crystals (Table 1).

\section{Reaction of 1 with chloro acetic acid : formation of 8 .}

A mixture of monochloro acetic acid $(0.01 \mathrm{~mol})$ and $1(0.01 \mathrm{~mol})$ in $(20 \mathrm{ml})$ of aqous $\mathrm{NaOH}(10 \%)$ was heated under reflux for $4 \mathrm{hrs}$. after cooling it was diluted with water, extracted with ether, washed well and recrystallised from ethanol to give 8 as gray crystals (Table 1).

\section{Condensation of 8 with salicylaldelyde : formation of 9.}

To a well stirred suspension of the acid derivative $8(0.01 \mathrm{~mol})$ in $(25 \mathrm{ml})$ of absolute ethanol containing sodium ethoxide $(0.01 \mathrm{~mol})$ was added dropwise salicylaldelyde $(0.01 \mathrm{~mol})$ and stirring was continued for $3 \mathrm{hrs}$. while cooling the reaction mixture was left overnight then diluted with water containing $10 \mathrm{ml}$ of $\mathrm{NaOH}(10 \%)$. The product separated was collected, washed and recrystallized from P.E (b.p $60-80^{\circ} \mathrm{C}$ ) to give 9 as orange crystals (Table 1).

\section{Thionation of 1 : formation of thiophthalazine 10}

A mixture of $1(0.01 \mathrm{~mol})$ and phosphorus pentasulphide $(0.01 \mathrm{~mol})$ in $30 \mathrm{ml}$ of dry xylene was refluxed for $2 \mathrm{hrs}$. It was then filtered off while hot then left to cool. The solid product was recrystallized from ethanol to give 10 as yellow crystals (Table 1).

\section{Reaction of 10 with Amines : Formation of 11a,b}

A mixture of $10(0.01 \mathrm{~mol})$ and amines, namely benzylamine and/or diphenylamine $(0.01 \mathrm{~mol})$ in $30 \mathrm{ml}$ of ethanol was refluxed for $6 \mathrm{hrs}$. After concentration and cooling the solid that separated was collected and recrystallized from ethanol to give 11a as beige crystals and $11 \mathrm{~b}$ as yellow crystals (Table 1). 


\section{Reaction of 10 with Hydrazine hydrate : Formation of 12}

A mixture of $10(0.01 \mathrm{~mol})$ and hydrazine hydrate $(0.01 \mathrm{~mol})$ in $30 \mathrm{ml}$ of ethanol was heated under reflux for $8 \mathrm{hrs}$. After concentration and cooling the solid product collected and recrystallized from ethanol to give 12 as brownish red crystals

Reaction of (12) with Benzaldehyde : Formation of (13)

A solution of $12(0.01 \mathrm{~mol})$ in $30 \mathrm{ml}$ ethanol was treated with benzaldehyde $(0.01 \mathrm{~mol})$ and one drop of pipridine, the mixture was heated under reflux for $3 \mathrm{hrs}$. The crystals separated on cooling were filtered off and recrytallized from ethanol to give 13 as yellow crystals (Table 1).

\section{Reaction of 10 with Acrylonitrile : Formation of 14.}

A mixture of $10(0.01 \mathrm{~mol})$ and acrylonitrile $(0.01 \mathrm{~mol})$ in $30 \mathrm{ml}$ of pyridine was refluxed for $3 \mathrm{hrs}$. it was then poured into ice - dilute $\mathrm{HCl}$ and the product that separated was collected, washed well with water then recrystallized from ethanol to give 14 as brown crystals (Table 1).

\section{Reaction of 10 with phenylisothiocyanate : Formation of 15}

A mixture of $10(0.01 \mathrm{~mol})$ and phenylisothiocyanate $(0.01 \mathrm{~mol})$ in $30 \mathrm{ml}$ of pyridine was heated under reflux for $6 \mathrm{hrs}$ after cooling it was poured into ice dilute $\mathrm{HCl}$ and the product separated was collected and washed with water and then recrystallized from ethanol to give 15 as yellow - brown crystals (Table 1).

\section{Alkylation of (10) with Ethylbromoacetate: Formation of 16}

A mixture of $10(0.01 \mathrm{~mol})$, ethylbromoacetate $(0.01 \mathrm{~mol})$ and anhydrous potassium carbonate $(0.04 \mathrm{~mol})$ in $50 \mathrm{ml}$ of dry acetone was refluxed for $24 \mathrm{hrs}$. It was filtered off on hot and poured into water. The product that separated was collected, washed well and recrystallized from methanol to give 16 as white crystals (Table 1).

\section{Reaction of 16 with Anthranilic acid : Formation of 17}

A mixture of $16(0.01 \mathrm{~mol})$ and anthranilic acid $(0.01 \mathrm{~mol})$ in $30 \mathrm{ml}$ butanol was heated under reflux for $10 \mathrm{hrs}$. After concentration and cooling the solid that separated was recrystallized from ethanol to give 17 as yellow crystals (Table 1).

\section{Action of Hydrazines on (16):Formation of 18}

A mixture of $16(0.01 \mathrm{~mol})$ and hydrazine hydrate $(0.01 \mathrm{~mol})$ in $30 \mathrm{ml}$ ethanol was heated under reflux for $6 \mathrm{hrs}$. After cooling the solid that separated collected and recrystallized from ethanol to give 18 as yellowish white crystals (Table 1). 
Table (1) : Physical and analysis data of the products

\begin{tabular}{|c|c|c|c|c|c|c|c|c|c|c|c|c|c|}
\hline \multirow{2}{*}{ Compound } & \multirow{2}{*}{$\begin{array}{l}\text { M.P. }\left({ }^{\circ}{ }^{\circ}{ }^{\circ}\right) \\
\text { Solvent of } \\
\text { crystallization }\end{array}$} & \multirow{2}{*}{$\begin{array}{l}\text { Yield } \\
\%\end{array}$} & \multirow{2}{*}{$\begin{array}{l}\text { Molecular } \\
\text { Formula }\end{array}$} & \multicolumn{5}{|c|}{ Found (\%) } & \multicolumn{5}{|c|}{ Calcd (\%) } \\
\hline & & & & C & $\mathrm{H}$ & $\mathrm{N}$ & S & $\mathrm{Cl}$ & $\mathrm{C}$ & $\mathrm{H}$ & $\mathrm{N}$ & S & $\mathrm{Cl}$ \\
\hline 2 & $\begin{array}{l}190 \\
\text { EtOH }\end{array}$ & 60 & $\mathrm{C}_{15} \mathrm{H}_{11} \mathrm{ON}_{2} \mathrm{Cl}$ & 65.3 & 4.5 & 9.83 & & 12.5 & 65.4 & 4.0 & 10.5 & & 13.1 \\
\hline 3 & $\begin{array}{l}220 \\
\text { EtOH }\end{array}$ & 70 & $\mathrm{C}_{17} \mathrm{H}_{13} \mathrm{O}_{2} \mathrm{~N}_{3}$ & 69.0 & 4.5 & 13.8 & & & 70.1 & 4.46 & 14.4 & & \\
\hline 4 & $\begin{array}{l}195 \\
\text { EtOH }\end{array}$ & 60 & $\mathrm{C}_{22} \mathrm{H}_{15} \mathrm{O} 2 \mathrm{~N}_{3}$ & 73.7 & 4.2 & 11.5 & & & 74.8 & 4.2 & 11.8 & & \\
\hline 5 & $\begin{array}{l}160 \\
\text { EtOH }\end{array}$ & 65 & $\mathrm{C}_{15} \mathrm{H}_{17} \mathrm{ON}_{4}$ & 65.8 & 5.8 & 19.9 & & & 66.9 & 6.3 & 20.8 & & \\
\hline 6 & $\begin{array}{l}210 \\
\text { EtOH }\end{array}$ & 60 & $\mathrm{C}_{17} \mathrm{H}_{16} \mathrm{O}_{2} \mathrm{~N}_{2}$ & 72.3 & 5.6 & 9.4 & & & 72.8 & 5.8 & 10.0 & & \\
\hline 7 & $\begin{array}{l}210 \\
\text { EtOH }\end{array}$ & 50 & $\mathrm{C}_{22} \mathrm{H}_{16} \mathrm{O}_{2} \mathrm{~N}_{4}$ & 70.3 & 4.1 & 16.9 & & & 71.7 & 4.3 & 17.3 & & \\
\hline 8 & $\begin{array}{l}190 \\
\text { EtOH }\end{array}$ & 75 & $\mathrm{C}_{17} \mathrm{H}_{14} \mathrm{O}_{4} \mathrm{~N}_{2}$ & 66.3 & 4.5 & 8.6 & & & 67.5 & 4.6 & 9.2 & & \\
\hline 9 & $\begin{array}{l}110 \\
\text { P.E (60-80) }\end{array}$ & 70 & $\mathrm{C}_{24} \mathrm{H}_{18} \mathrm{O}_{5} \mathrm{~N}_{2}$ & 69.0 & 4.4 & 6.1 & & & 69.5 & 4.4 & 6.7 & & \\
\hline 10 & $\begin{array}{l}220 \\
\text { EtOH }\end{array}$ & 60 & $\mathrm{C}_{15} \mathrm{H}_{12} \mathrm{ON}_{2} \mathrm{~S}$ & 66.7 & 4.1 & 10.3 & 10.9 & & 67.1 & 4.47 & 10.44 & 11.94 & \\
\hline $11 \mathrm{a}$ & $\begin{array}{l}160 \\
\text { EtOH }\end{array}$ & 70 & $\mathrm{C}_{22} \mathrm{H}_{19} \mathrm{ON}_{3}$ & 77.0 & 5.5 & 11.93 & & & 77.4 & 5.5 & 12.3 & & \\
\hline $11 \mathrm{~b}$ & $\begin{array}{l}170 \\
\text { EtOH }\end{array}$ & 70 & $\mathrm{C}_{27} \mathrm{H}_{22} \mathrm{ON}_{3}$ & 79.0 & 5.4 & 10.1 & & & 80.1 & 5.4 & 10.39 & & \\
\hline 12 & $\begin{array}{l}150 \\
\text { EtOH }\end{array}$ & 50 & $\mathrm{C}_{15} \mathrm{H}_{13} \mathrm{ON}_{4}$ & 67.0 & 4.8 & 20.3 & & & 67.9 & 4.9 & 21.13 & & \\
\hline 13 & $\begin{array}{l}180 \\
\text { EtOH }\end{array}$ & 60 & $\mathrm{C}_{22} \mathrm{H}_{18} \mathrm{ON}_{4}$ & 74.3 & 4.9 & 14.93 & & & 74.57 & 5.0 & 15.8 & & \\
\hline 14 & $\begin{array}{l}160 \\
\text { EtOH }\end{array}$ & 65 & $\mathrm{C}_{18} \mathrm{H}_{15} \mathrm{ON}_{3} \mathrm{~S}$ & 67.0 & 4.3 & 13.0 & 8.89 & & 67.2 & 4.6 & 13.08 & 9.96 & \\
\hline 15 & $\begin{array}{l}220 \\
\text { EtOH }\end{array}$ & 70 & $\mathrm{C}_{22} \mathrm{H}_{17} \mathrm{ON}_{3} \mathrm{~S}_{2}$ & 65.0 & 4.1 & 10.0 & 14.9 & & 65.55 & 4.2 & 10.42 & 15.88 & \\
\hline 16 & $\begin{array}{l}120 \\
\mathrm{MeOH}\end{array}$ & 40 & $\mathrm{C}_{19} \mathrm{H}_{18} \mathrm{O}_{3} \mathrm{~N}_{2} \mathrm{~S}$ & 64.1 & 5.0 & 7.4 & 8.8 & & 64.4 & 5.8 & 7.9 & 9.03 & \\
\hline 17 & $\begin{array}{l}140 \\
\text { EtOH }\end{array}$ & 50 & $\mathrm{C}_{17} \mathrm{H}_{16} \mathrm{O}_{2} \mathrm{~N}_{2} \mathrm{~S}$ & 64.3 & 5.0 & 8.2 & 9.6 & & 65.3 & 5.12 & 8.97 & 10.25 & \\
\hline 18 & $\begin{array}{l}180 \\
\text { EtOH }\end{array}$ & 50 & $\mathrm{C}_{24} \mathrm{H}_{17} \mathrm{O}_{3} \mathrm{~N}_{3} \mathrm{~S}$ & 67.1 & 3.5 & 9.5 & 7.3 & & 67.4 & 3.98 & 9.8 & 7.49 & \\
\hline
\end{tabular}




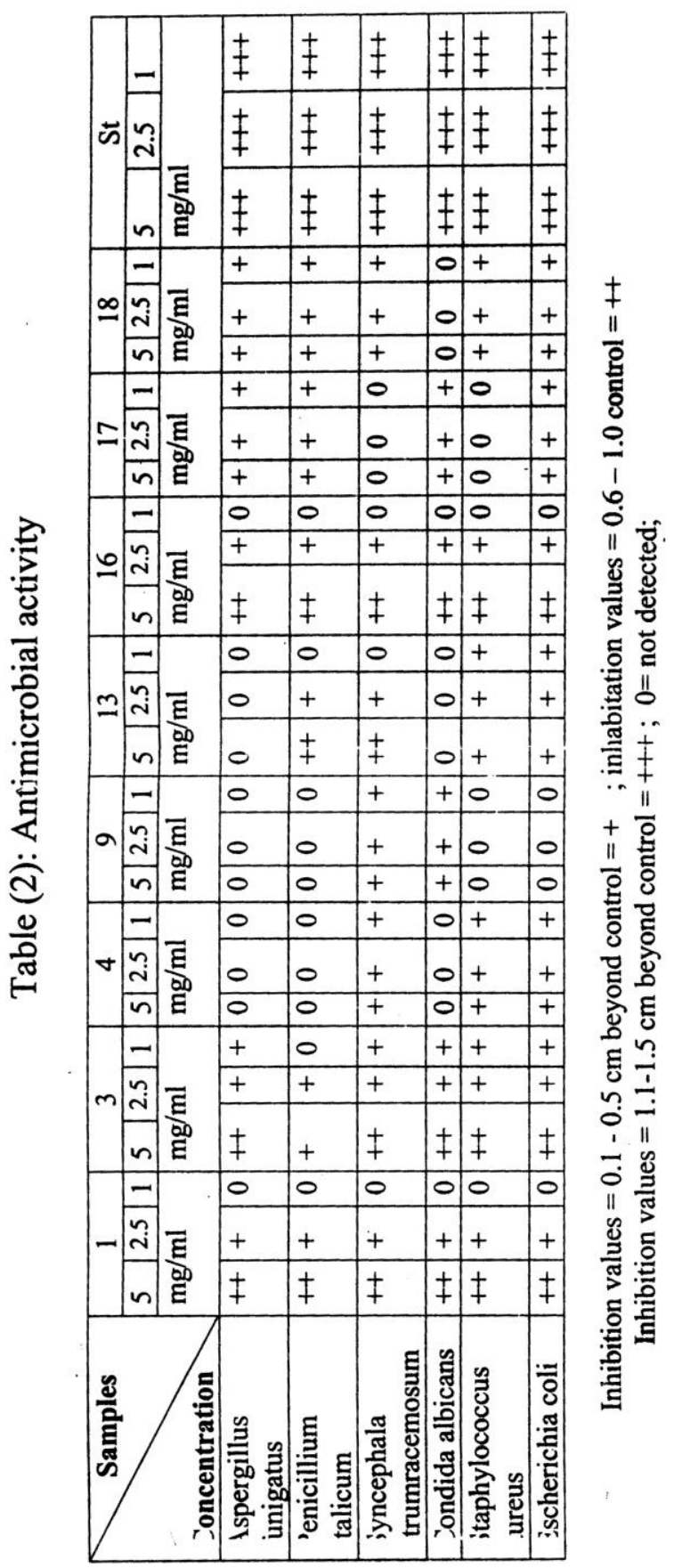




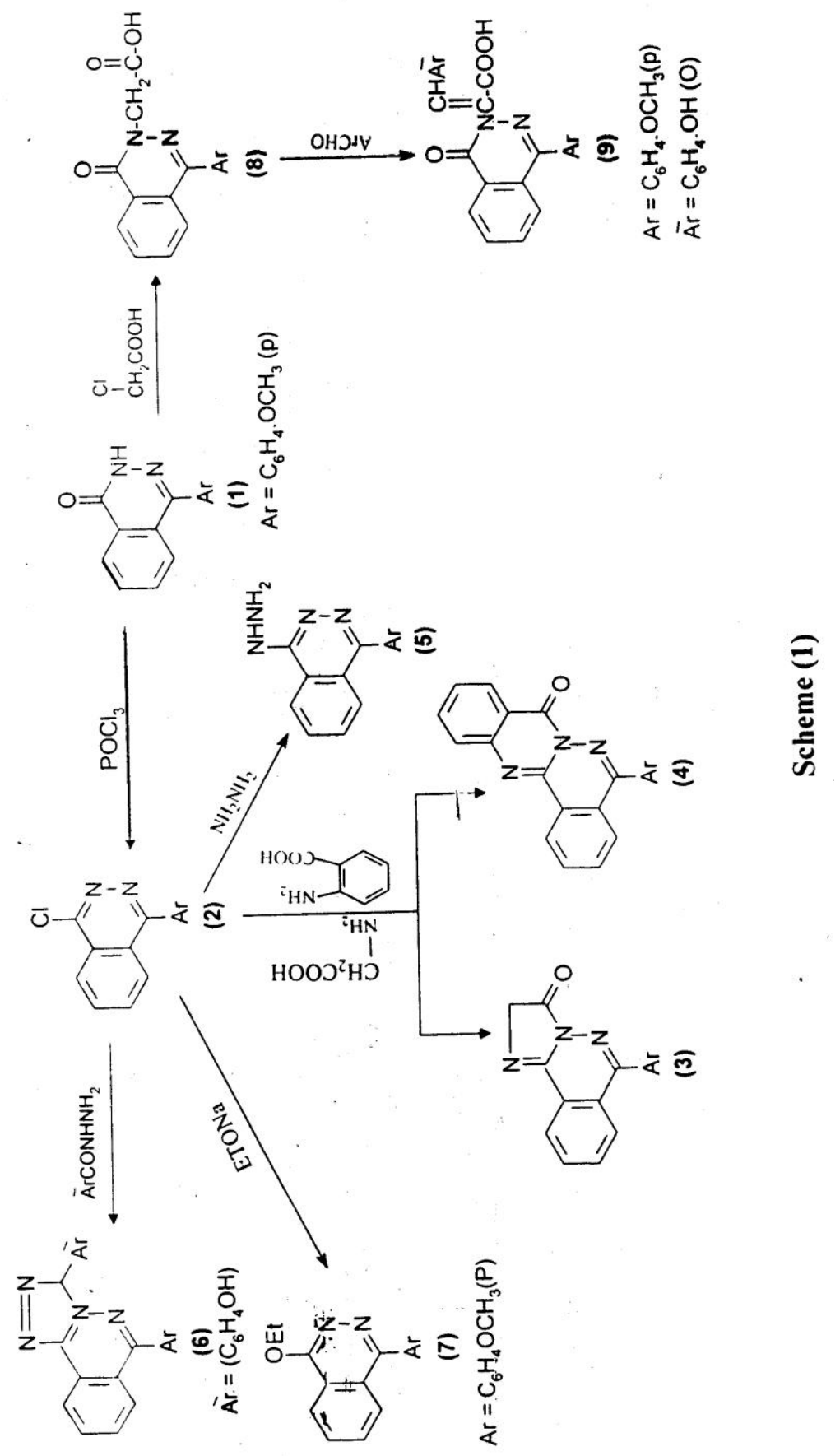




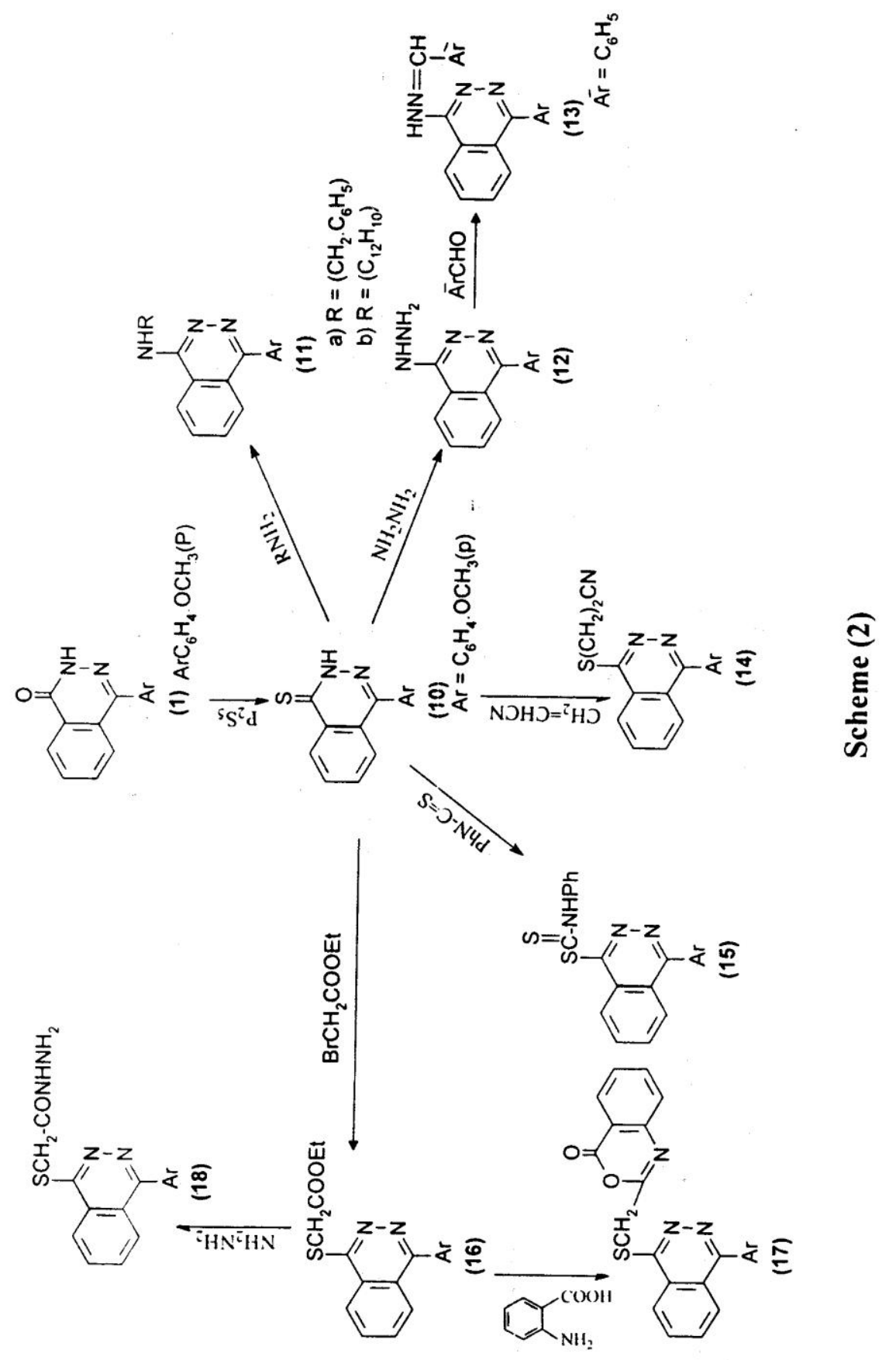




\section{References}

1. N.T. A. DAWOOD, S.M. ABDEL-GAWAD AND F.M.A. SOLIMAN, Boll.Chim Farmacs 140 (3) (2001).

2. F.M.A. SOLIMAN, L.M. SOUKA AND N.F. ABD EL-GHAFFAR, Revue Roumaine De Chimie, 1994, 39(7), 827- 832.

3. R.BUCHMAN, JAMES. A. SCOZZIE, ZAVENS, ARIAN, RICHARD. D, HEILMAN, DON A. J. Rippin, W. J. Pyne, and Richard Matthews, J.Med, Chem. 23,1398 (1980).

4. El-HASHASH, M. A, EL-NAGDY, S. I. AND SALEH, R. M. J. Chem. Eng. Datd 1984,29,391.

5. J. D. ALBRIGHT, D. B. MORAN, W. B. WRIGHT, J. B. COLlins, B.BEER, A. S. LIPPA, E. N. J. Greenblat. J. Med. Chem, (1981),24,592.

6. SALEH AL-MOUSAWI, ELIZABETH JOHN AND NAJAT AL-KANDERY. J. Heterocyclic Chem., 41, 381 (2004).

7. EL-DEEN, I, M, MOHAMED , S, M. Indian, J. of Heterocyclic Chem,2 (1993),233-236.

8. R. M. SALEH, Indian, J. Chem, 30B(1991), 313.

9. I.M.EL-DEEN, S. M. MOHAMED, M. M. ISMAIL AND M.ABDEL-M Egid, Indian, J. of Heterocyclic Chem 31b (1992),310.

10. SHARMAH, S.C. AND BAHEL, S. C.J. Indian Chem. Soc., Li, 877 (1982).

11. A.Y. SOLIMAN, N. B. EL-ASSY.F.EL-SHAHED, M.EL-KADY, I.M.EL-DEEN, Indian J., Chem, 29B (1990), 326.

12. PETER H. GEYLIN, STEWVEN A. RAW, AND RICHARD J. K. Taylor. Arkivoc (2007) 37-45. 